\title{
Article
}

\section{Small Heat Source Used for Combustion of Wheat-Straw Pellets}

\author{
Marian Pafcuga *, Michal Holubcik (D), Peter Durcansky (D), Andrej Kapjor and Milan Malcho
}

check for updates

Citation: Pafcuga, M.; Holubcik, M.; Durcansky, P.; Kapjor, A.; Malcho, M. Small Heat Source Used for Combustion of Wheat-Straw Pellets. Appl. Sci. 2021, 11, 5239. https:// doi.org/10.3390/app11115239

Academic Editors: Joachim Müller and Hans Oechsner

Received: 11 May 2021

Accepted: 1 June 2021

Published: 4 June 2021

Publisher's Note: MDPI stays neutral with regard to jurisdictional claims in published maps and institutional affiliations.

Copyright: (c) 2021 by the authors. Licensee MDPI, Basel, Switzerland. This article is an open access article distributed under the terms and conditions of the Creative Commons Attribution (CC BY) license (https:// creativecommons.org/licenses/by/ $4.0 /)$.
Department of Power Engineering, Faculty of Mechanical Engineering, University of Žilina, Univerzitna 1, 01026 Žilina, Slovakia; michal.holubcik@fstroj.uniza.sk (M.H.); peter.durcansky@fstroj.uniza.sk (P.D.); andrej.kapjor@fstroj.uniza.sk (A.K.); milan.malcho@fstroj.uniza.sk (M.M.)

* Correspondence: marian.pafcuga@fstroj.uniza.sk

\begin{abstract}
Wheat straw, as a secondary waste agricultural product, presents a potential renewable source of energy. It is necessary to design simple heat sources to achieve better usage. As part of an analysis of heat sources, a tubular type of heat exchanger was reviewed. The design of the exchanger was focused on the smallest possible dimensional requirements, low costs, high reliability and easy maintenance. We chose a tubular type of heat exchanger. In our case, flue gas flows through the tubes, and water flows outside of the tubes. This type of exchanger allows for continuous cleaning, but also simple maintenance, even in case of equipment failure. It is possible to replace individual parts (pipes) of equipment that are exposed to the adverse corrosive effects of biomass flue gases. A mathematical model was composed to compute the construction of a heat source. The model was verified by CFD simulation. The main idea of this design is modularity. The composed model can be used to design a series of similar heat sources with different levels of power, and which, as it is of maximal availability for this type of construction, increase use of waste straw as fuel by small farms.
\end{abstract}

Keywords: wheat-straw; combustion; CFD; small heat source; boiler

\section{Introduction}

The use of alternative energy resources has risen in recent years due to many European Union initiatives. Fossil fuels are being replaced by electric energy, generated from various renewable energy sources, for example wind energy or solar energy. Electricity is also generated in biogas facilities, where waste, or secondary resources, are utilized in biogas reactors.

Renewable resources also play a significant role in heat production where solar energy is also used. Waste has some potential, as a secondary resource as well. Advanced waste recycling and the use of waste as an energy commodity is accepted across many countries. Many countries have already used use household waste to produce heat and electricity using waste incineration plants. Agricultural products are used as well; for example on fast growing plants. Waste or secondary products in agriculture have been used for many years, and they are considered possible energy resources, not only for biogas plants, but also as a direct resource for heat generation. One of such resources is straw and similar by-products in agriculture. Scheme of straw production is shown in Figure 1.

There are many initiatives that handle straw as energy resource. One of the most important was the IEA initiative in the early 1990s [1]. In this study, authors compared potential and real use of straw in energy generation across five European countries: United Kingdom, Denmark, Sweden, Netherlands and Austria. The main goal of this activity was to study straw and agricultural by-products utilization for heat or electricity generation. This study identified some barriers which make the use of straw difficult; for example, the difficult organization of straw deliveries, the very light economic impact, and also some skepticism against straw and other similar resources. Straw was extensively used for heating and combined heat power production only in Denmark. Approximately 1 million tons of straw was documented by the initiative for use of heat or electricity production 
in Denmark. Straw was also used for co-firing with coal in some power plants. Other countries used straw on limited scale. The initiative also identified some key aspects for influencing future use of straw:

- The time required to collect the straw is very limited, therefore sufficient harvesting capacity is needed;

- Straw bales with specific properties, for example density and shape, are required;

- Straw storage methods are important to reduce total costs;

- Using straw briquettes or pellets is not economic;

- A decentralized use of straw might be interesting.

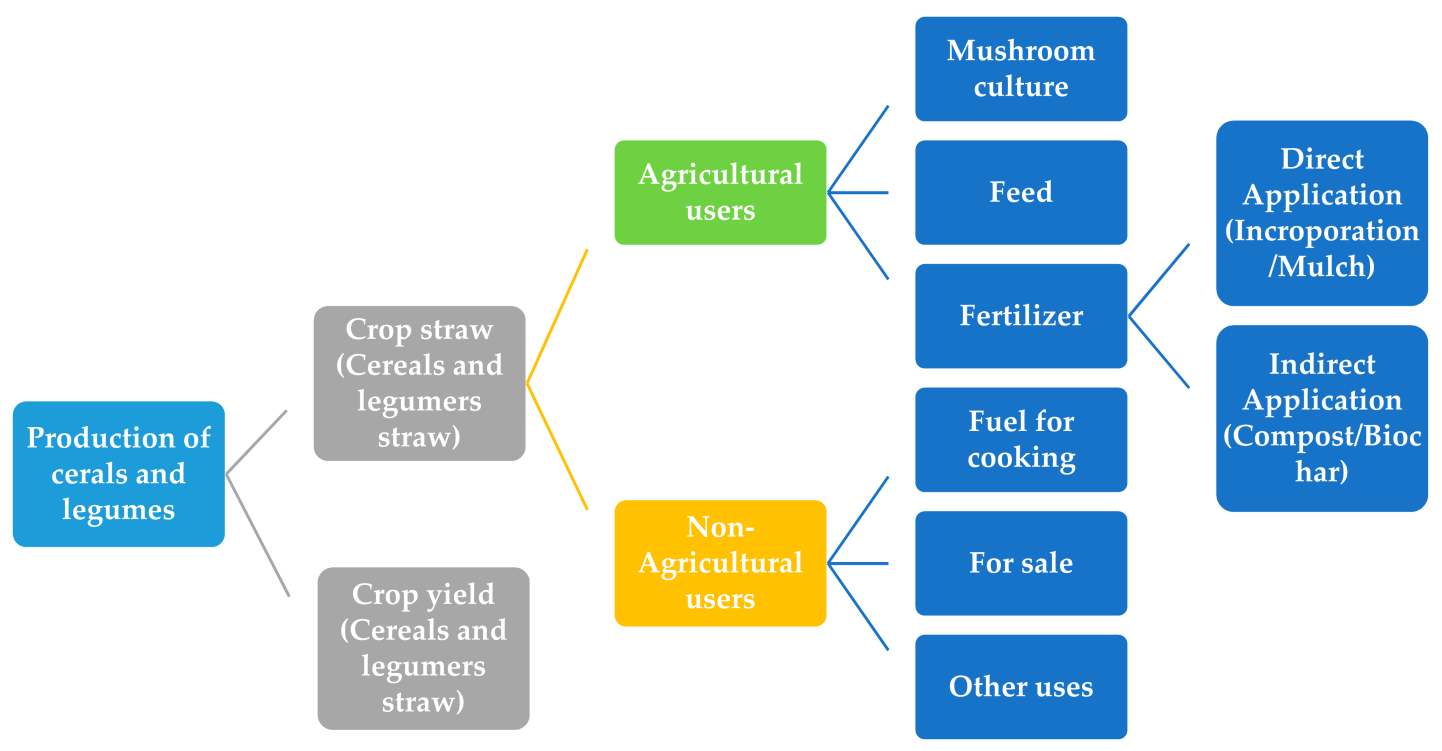

Figure 1. Scheme of legumes and cereals production.

A few years later, in another study [2], the authors focused on two countries from previous research, Sweden and Denmark. The authors analyzed, in their study, biomass energy systems with 13 examples where straw was used as main fuel, or as secondary fuel in combination with another biomass. The examined power levels ranged from small local heat production up to a large combined heat and power plants. Small heat sources using straw were mainly utilized by local farms with their own production. The authors visited all processed sites and interviewed key persons in these facilities. They also classified farm entrepreneurs according to study of Alsos et al. [3]. In this study, the authors also examined the reasons for the engagement or motivation of farmers to use new technologies as a use of straw for heat or electricity production. In their article, Alsos et al. [3] also identified three categories of farmers: (1) pluriactive farmers, those who seek new ways to increase income on the farm; (2) resource-exploiting farmers, who want to utilize material resources; and (3) portfolio farmers, who desire to exploit business opportunities and are not attached to any farming traditions.

Local contexts of straw as an energy resource have been also examined in a study [2] of Sweden and Denmark. In Sweden, the market was incipient and many projects for straw use started due to the introduction of a carbon tax on fossil fuels. The straw market was not established, but the new facilities had been built [4]. Voytenko et al. mentioned in [2] only two dedicated working straw-fired power plants.

Straw is used in Denmark on a wide range of scales, with many different purposes. The government has created subsidy schemes for straw-fired power plants and guaranteed price for power generation. Small straw-fired heat sources are located on private farms with grain production [2].

Recently, many studies have been written with a focus on biomass use for energy generation. For example, Perea et al. focused on the use of agricultural by-products and 
industrial residues as a substitution for fossil fuels in scientific publications [5]. They identified the rising interest in research into renewable sources and their use for energy generation. One of the main topics, as mentioned in [5], is decentralized energy generation from biomass as a carbon-neutral energy source. Agricultural by-products or residues are presented as increasingly used solid biofuel. Many of the mentioned publications were from Eastern Europe. One of the latest related works is Gradziuk et al.'s study [6]. The authors provide a detailed forecast of biomass production potential. The article is focused on straw utilization in Poland, where from up to 8.78 million hectares of straw can be provided as a by-product. The presented model is based on production, demand and surplus balance of straw utilized in the agricultural sector. The authors have also taken into account the need or demand for straw for fertilizing. The model was based on and adjusted to statistical data in the years from 1999 to 2019 for selected plants, from basic cereals to other mixtures. Mazurkiewicz et al., Kujawa et al. and Edwards et al. [7-9], were similarly focused on the main factors that affect the possible use of straw for energy purposes, which are produced volume, production stability, and periodicity.

Elbersen et al. [10] focused on countries where straw is already used, and compared them to countries with significant possibilities for straw energy use, for example the above-mentioned Poland, Germany, Romania and Slovakia. The structure of agriculture, mainly area structure, or farm size, according Gradziuk et al. can have an impact on straw availability, due to limited use of high-performance ballers [6].

However, in other countries, as mentioned in a study by Patience et al. in 2019, in different market conditions, straw is used barely. The authors focused on the African country Ghana, where large amounts of crop residues are often abandoned in heaps or simply burnt on the fields. The total straw amount can be estimated only based on statistical data from crop production, and that is a major challenge. Straw as a resource is ignored in many of developing countries. This lack of interest is caused by the measurement problem: how to exactly produce and measure the same product, for example a straw bale [11]. Another issue is the management of resources, not only raw materials, but also the handling and processing capacities that are partly missing in these countries [11].

The simple use of straw for heating purposes with adequate small heat sources can have a significant impact on resource utilization for many developing countries, and ultimately lead to a reduction in the use of fossil fuels, which can enable emissions reduction. The idea of small straw-fired heat sources from Denmark can be applied also in developing countries.

A proposed heat source should be able to handle different types of fuels. As mentioned in Moliner et al. [12], not only cereals, but also rice by-products could be a significant resource in developing countries. Rice straw combined with wood in the form of pellets could be used for heat generation with low emissions.

Straw is important in agricultural production, where it is mainly used as fodder or bedding, but straw surplus is always created by changing the structure of agricultural production. This surplus can be used as an energy resource with other by-products [13].

\section{Design and Method}

Direct biomass firing is the most common technique for every kind of biomass fuel conversion into energy [14]. Some heat sources for biomass burning should be able to handle differences of fuel quality and fluctuations. It is caused by seasonal changes or different available types of fuel during the year [14].

There are different types of biomass boilers or furnace constructions, with different combustion processes. For example, grate furnaces, gasifying boilers or fire-through boilers, co-firing boilers, but also boilers for straw burning in bale form, where minimal handling effort is desired [15].

Before designing a boiler, it is necessary to take into account possible emissions and heat output differences due to various burning conditions in cases of burning straw 
biomass [16]. Another problem is ash melting and deposition [17]. The construction of a new proposed heat source has to enable simple cleaning and maintaining.

The design is focused on the problems of over burning the straw, the design of an arrangement to prevent the clogging of the exchanger, easy maintenance of the boiler, and the low cost of boiler.

It is necessary to work with basic boundary conditions, such as maximum dimensions, a certain output, and also the type of fuel that will burn in the proposed boiler. The proposed heat power output of the boiler, which counts as its main target of use small farms and houses, is $20 \mathrm{~kW}$. The type of fuel is chosen to be pellets of wheat straw. This type of fuel can have different properties of burning.

Therefore, in our case, we decided for a tubular type exchanger. In comparison to the small heat source of Dongii Wang [18], which is used to burn rice pellets and consists of two combustion chambers and plate heat exchangers, our heat source is designed on a similar principle as a heat source designed by Mladenovic [15]. It uses a tubular heat exchanger and flue gas flows through the pipes. The main difference is in the connection between the two passes of the heat exchanger, which, in our case, are on top of the heat exchanger. This is due to the location of the combustion chamber. This type of construction allows more modifications, such as using turbulizators, introducing baffles to the combustion chamber, and on top of the boiler. The result will be better combustion conditions for the straw pellets.

The suitable construction of the boiler is adapted to the spatial conditions of small boiler rooms, because it will be used for heating small agricultural buildings and family houses. After considering the insulation, which can reach a thickness of $75 \mathrm{~mm}$ even with the construction, and the minimum size of the installed boiler room entrance door, the maximum possible floor width has to be $400 \mathrm{~mm}$. The maximum height of the device must not exceed $1.6 \mathrm{~m}$. The scheme of the designed solution is shown in Figure 2. Proposed device used to combustion of wheat-straw pellets. The main idea of designing the boiler is to create a boiler that consists of modules. These modules can be used to build whole new equipment with different heat power levels. In addition, when it is used in construction, it consists of a two pass heat exchanger, so during failure or while fixing a damaged part of heat exchanger, the second part can be used to heat the building with reduced heat power.

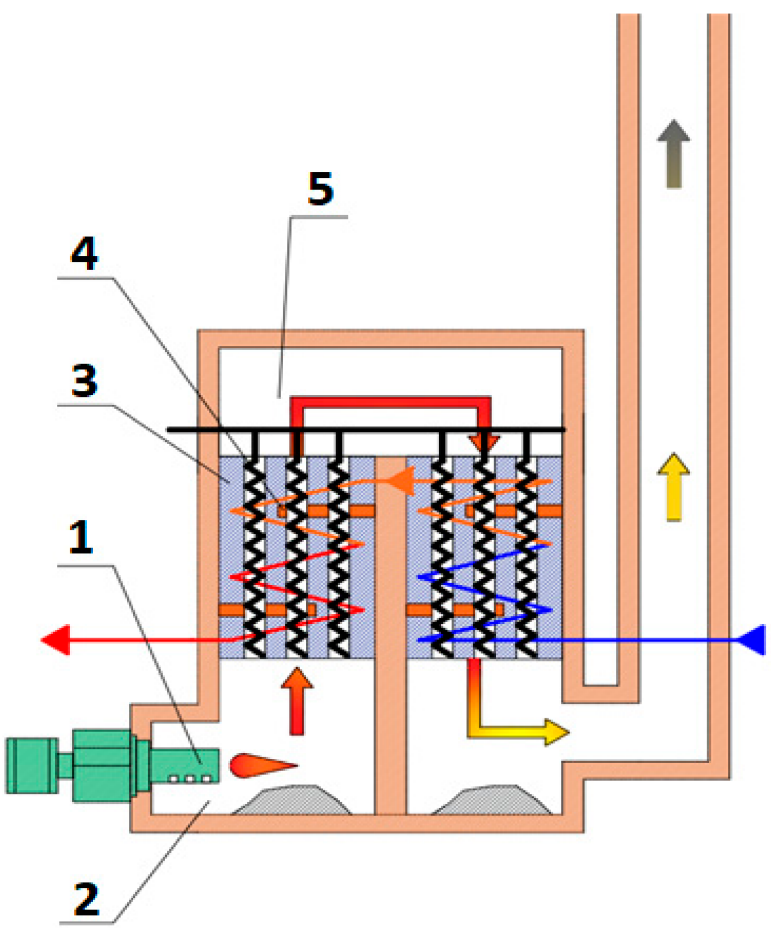

Figure 2. Proposed device used to combustion of wheat-straw pellets. 
The proposed device shown in Figure 2 consists of a rotary burner (1), an inlet chamber with an ashtray (2), primary and secondary heat exchangers (3), a top chamber (5) and a chimney chamber.

\subsection{Design of Burner}

It is necessary to use a burner which allows the burning of different types of biomass to use as fuel as well as wheat straw. This makes a rotary burner the best choice; a rotary burner with construction, which can burn fuels of different qualities. Its construction is designed to obtain the highest possible energy from combustion. Improved thermal efficiency and reduced pollutants have been achieved by using a rotary combustion chamber. A screw feed device is used to control the amount of combusted biomass. Biomass pellets are fed from the spiral tube to the rotary combustion chamber. Secondary air is flowing into the rotary combustion chamber through the secondary air pores to make the biomass particles burn completely $[19,20]$.

Because of the solution-meaning that secondary air flowing into the rotary combustion chamber can be continuously adjusted-the precisely matched amount of air was allowed inside the chamber to achieve the optimal process of combustion of pellets with different qualities, and highest possible energy achievement, starting from igniting the fire throughout all stages of maintaining the fire, after reaching the preset temperature of combustion, up to the fire suppression [19].

\subsection{Design of the Combustion Chamber}

The design of the combustion chamber is based on the idea of simple assembly and modularity of our heat source. The construction of the chamber, as shown in Figure 3, consists of a plate (1), which allows connection of rotary burner, furnace (2), and profiles (3), which also allows a grate under to heat exchanger to be introduced and different type of burner to be used. The flame from the burner is distributed through the chamber to the first stage heat exchanger. On top of the chamber is placed the heat exchanger.

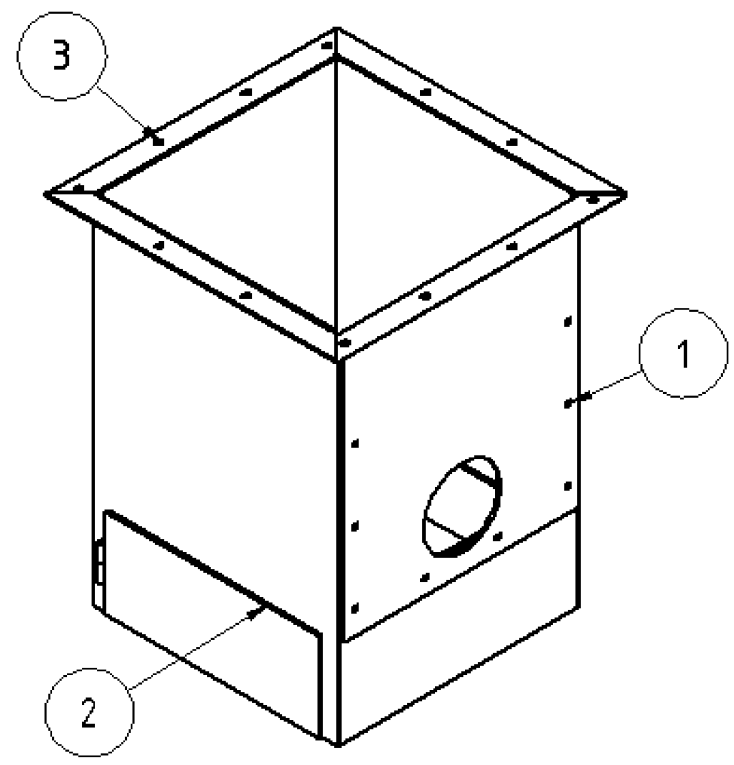

Figure 3. Combustion chamber.

\subsection{Design of the Heat Exchanger}

We know there to be various divisions of types of exchangers in terms of construction and type of media used, and according to the purpose of use and the direction of the flow of heat transfer media. During the design of the exchanger, we placed high emphasis on the lowest possible dimensional requirements, low costs, high reliability and easy maintenance. During the process of burning biomass, it is necessary to take into account in particular the 
simplicity of construction, but also the easiest possible maintenance of the equipment. The combustion of biomass, especially straw, produces emissions of solid pollutants, which gradually pollute the heat exchanger.

We have chosen a tubular type of heat exchanger. In our case, flue gas flows through tubes, and water flows around the tubes. This type of exchanger enables the introduction of continuous cleaning, but also simple maintenance, when, even after equipment failures, it is possible to replace individual parts (pipes) of the equipment that are exposed to the adverse corrosive effects of biomass flue gases. In the event of a fault, the device can also work with only one exchanger with reduced power. In this way, it is possible to maintain the functionality of the device; maintaining the operation of the heating system, repairing a non-functional part of the exchanger and quickly re-commissioning the device.

\subsubsection{Numerical Design of Heat Exchanger}

To calculate the heat exchanger properties, we need to know the input parameters, such as the fuel to be used, and the maximal size of the heat exchanger. As was mentioned before, our boiler should not be wider than $600 \mathrm{~mm}$, and the minimal depth of insulation is $100 \mathrm{~mm}$. The maximal width and depth of the exchanger was set to $400 \mathrm{~mm}$. The heat exchanger is made of steel. Our boiler will be used for the combustion of wheat-straw pellets. The target heat power of the heat exchanger was set to 20 kilowatts. A model based on criterial equations was designed to simply calculate the optimal dimensions of the exchanger with concrete type of used fuel. The calculation scheme is described in Figure 4.

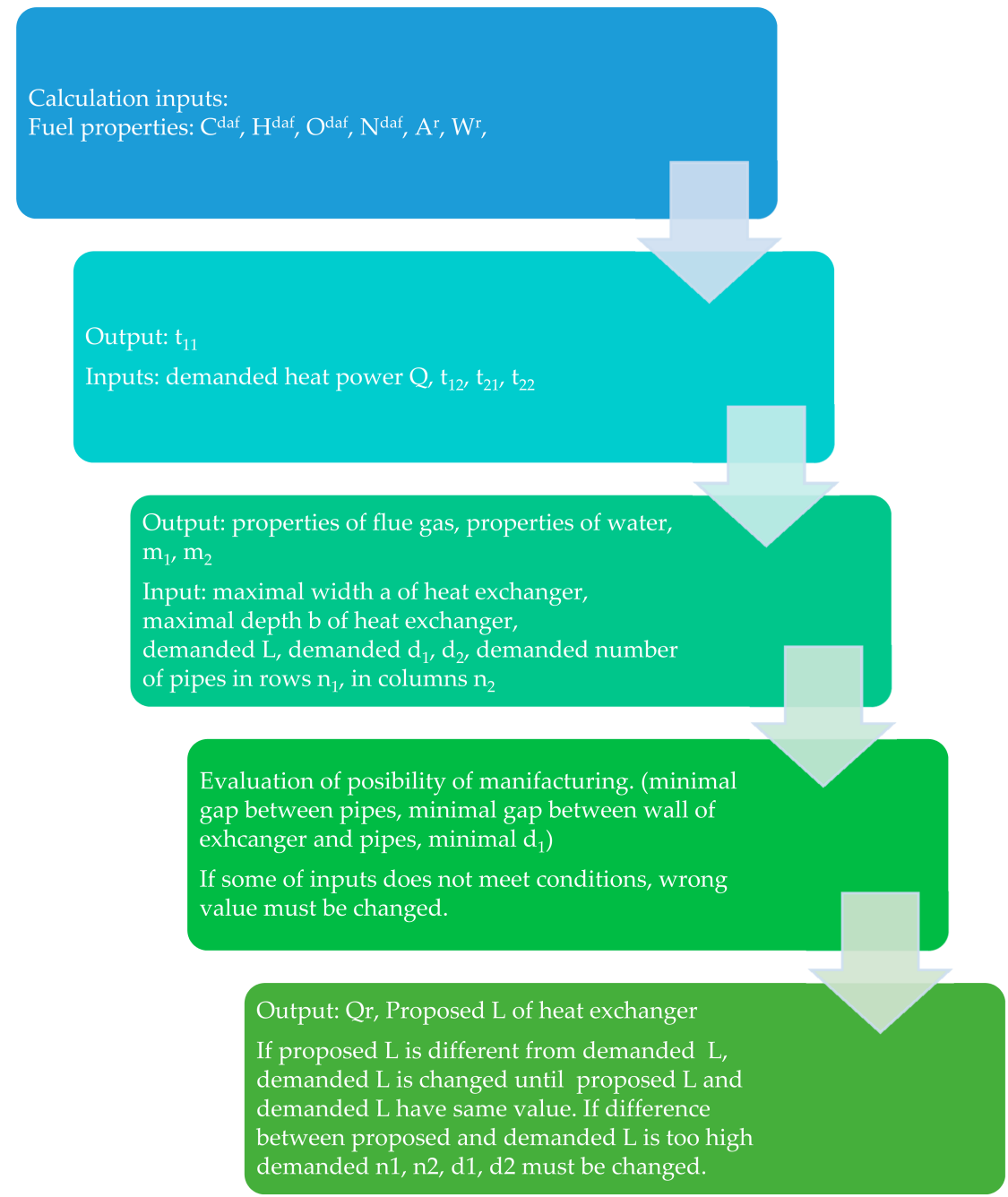

Figure 4. Scheme of calculations of heat exchanger's dimensions. 
From Figure 4 it is obvious that, firstly, we have to calculate input parameters of burning fuel from Table 1. Chemical composition of combusted fuel (wheat straw). [21]

Table 1. Chemical composition of combusted fuel (wheat straw) [21].

\begin{tabular}{lcc}
\hline \multicolumn{3}{c}{ Chemical Composition of Fuel } \\
\hline$C^{\text {daf }}$ & $46.05 \%$ \\
$H^{\text {daf }}$ & $5.93 \%$ \\
$O^{\text {daf }}$ & $42.95 \%$ \\
$N^{d a f}$ & $0.58 \%$ \\
$A^{r}$ & $4.31 \%$ \\
$W^{r}$ & $7.7 \%$ \\
\hline
\end{tabular}

The calorific value of used fuel from the chemical composition of the fuel given in Table 1 is calculated by using Equation (1) [22-24].

$$
Q_{n}=\left[339 \times C^{d a f}+1029.7 \times H^{d a f}-108.8 \times O^{d a f}\right] \times\left[\frac{100-A^{r}-W^{r}}{100}\right]-W^{r} \times 25.1 \text {. (1) }
$$
Table 2.

Next step is calculation of proposed sizes of heat exchanger by using parameters from

Table 2. Heat exchanger design inputs.

\begin{tabular}{ccc}
\hline Parameter & Value & Unit \\
\hline Inlet temperature of flue gas $\left(t_{11}\right)$ & 1040 & ${ }^{\circ} \mathrm{C}$ \\
Outlet temperature flue gas $\left(t_{12}\right)$ & 150 & ${ }^{\circ} \mathrm{C}$ \\
Inlet temperature of water $\left(t_{21}\right)$ & 50 & ${ }^{\circ} \mathrm{C}$ \\
Outlet temperature of water $\left(t_{22}\right)$ & 80 & ${ }^{\circ} \mathrm{C}$ \\
Demanded heat power $(Q)$ & 20 & $\mathrm{~kW}$ \\
\hline Calculated Parameter & Value & $\mathrm{J} \cdot \mathrm{kg}^{-1} \mathrm{~K}^{-1}$ \\
\hline Specific heat capacity of flue gas $\left(c_{1}\right)$ & 1118.68 & ${ }^{\circ} \mathrm{C}$ \\
Specific heat capacity of water $\left(c_{2}\right)$ & 4180.56 & $\mathrm{~kg} \cdot \mathrm{s}^{-1}$ \\
Flow of flue gas $\left(m_{1}\right)$ & $2.0128 \times 10^{-2}$ & $\mathrm{~kg} \cdot \mathrm{s}^{-1}$ \\
Flow of water $\left(m_{2}\right)$ & $1.5968 \times 10^{-1}$ &
\end{tabular}

By Equations (2) and (3) the temperature of inlet flue gas, and the amount of inlet flue gas to heat exchanger were calculated.

$$
t_{11}=\frac{m_{p} \times Q_{n} \times \eta_{s p} \times(1-\varepsilon)+\lambda \times m_{s v-\min } \times\left[c_{s v p}\right] \times t_{s v}}{m_{s p} \times\left[c_{s p}\right]} .
$$

Heat balance equation:

$$
Q=m_{1} \times c_{1} \times\left(t_{11}-t_{12}\right)=m_{2} \times c_{1} \times\left(t_{22}-t_{21}\right) .
$$

In Equation (3), $Q$ is demanded power of heat exchanger (W), $m_{1}$ is flow of flue gas $\left(\mathrm{kg} \cdot \mathrm{s}^{-1}\right), c_{1}$ is specific heat capacity of flue gas $\left(\mathrm{J} \cdot \mathrm{kg}^{-1} \mathrm{~K}^{-1}\right), t_{11}$ is inlet temperature of flue gas $\left({ }^{\circ} \mathrm{C}\right), t_{12}$ is outlet temperature of flue gas $\left({ }^{\circ} \mathrm{C}\right), m_{2}$ is flow of water $\left(\mathrm{kg} \cdot \mathrm{s}^{-1}\right), c_{2}$ is specific heat capacity of water $\left(\mathrm{J} \cdot \mathrm{kg}^{-1} \mathrm{~K}^{-1}\right), t_{21}$ is inlet temperature of water $\left({ }^{\circ} \mathrm{C}\right), t_{22}$ is outlet temperature of water $\left({ }^{\circ} \mathrm{C}\right)$.

Specific heat capacity of flue gas [25]:

$$
c_{1}=\left(\frac{\left(t_{11}-t_{12}\right)}{2}\right)^{2} \times 9.991093 \times 10^{-5}+\frac{\left(t_{11}-t_{12}\right)}{2} \times 1.27767 \times 10^{-1}+1007.57 .
$$


Specific heat capacity of water [25]:

$$
c_{2}=4210-1.363 \times \frac{\left(t_{11}-t_{12}\right)}{2}+1.4 \times 10^{-3} \times\left(\frac{\left(t_{11}-t_{12}\right)}{2}\right)^{2}
$$

The overall heat transfer rate is calculated by the logarithmic mean temperature design method (LMTD) [25,26]:

$$
Q_{r}=h \times S \times \Delta t_{L N}
$$

where $Q$ represents heat transfer rate $(\mathrm{W}), \mathrm{k}$ is overall transfer coefficient $\left(\mathrm{W} \cdot \mathrm{m}^{-1} \cdot \mathrm{K}^{-1}\right)$ and $\Delta t_{L N}$ is logarithmic mean temperature gradient for counter flow $\left({ }^{\circ} \mathrm{C}\right)$.

Logarithmic mean temperature gradient is calculated from Equation 7 [25]:

$$
\Delta t_{L N}=\frac{\left(t_{11}-t_{21}\right)-\left(t_{12}-t_{22}\right)}{\ln \frac{\left(t_{11}-t_{21}\right)}{\left(t_{12}-t_{22}\right)}}
$$

Area of heat exchanger (Equation (6)) is calculated from inner diameter $d_{1}(\mathrm{~m})$, number of pipes in length $n_{1}$, number of pipes in width $n_{2}$ and length of heat exchanger $L(m)$ [25]:

$$
S=\pi \times d_{1} \times n_{1} \times n_{2} \times L
$$

We have to find the proper length of heat exchanger to achieve the demanded heat power of heat exchanger. Length of heat exchanger is calculated by Equation (9) [25]:

$$
L=\frac{k \times \Delta t_{L N}}{\pi \times d_{1} \times n_{1} \times n_{2} \times Q}
$$

Overall heat transfer coefficient $k$ is calculated by heat transfer coefficients on the flue gas side $h_{1}$ and water side $h_{2}$ [25]:

$$
k=\frac{1}{\frac{1}{h_{1}}+\frac{1}{h_{2}}} .
$$

For the flue gas side, we have to consider properties of flow, firstly we have to calculate velocity of flu gas flowing through pipes. Velocity $u_{1}$ is calculated from Equation (11) [25]:

$$
u_{1}=\frac{4 \times m_{1}}{\rho_{F G} \times \pi \times d_{1}^{2} \times n_{1} \times n_{2}},
$$

where are: $d_{1}(\mathrm{~m})$ inner diameter, number of pipes in length $n_{1}$, number of pipes in width $n_{2}$ and length of heat exchanger $L(\mathrm{~m}), \rho_{F G}\left(\mathrm{~kg} . \mathrm{m}^{-3}\right)$ density of flue gas, $m_{1}\left(\mathrm{~kg} . \mathrm{s}^{-1}\right)$ flow of flue gas.

Finding the type of flue gas flow is necessary to calculate the Reynolds number (Equation (12)) [25]:

$$
R e_{1}=\frac{u_{1} \times d_{1}}{\vartheta_{1}} .
$$

The Prandtl number is calculated by Equation (13) [25]:

$$
P r_{1}=\frac{c_{1} \times \mu_{1}}{\lambda} .
$$

The ratio of convective and conductive heat transfer at boundary fluid is named the Nusselt number. The Nusselt number is used to further the calculation of heat transfer coefficient. For laminar flow, it is calculated using Equation (12). For turbulent flow is calculated in Equation (14) [25]:

$$
N u_{1}=\frac{1.615 \times\left(R e_{1} \times P r_{1} \times D\right)^{1 / 3}}{L}, \operatorname{Re} \in(0,2000\rangle,
$$




$$
N u_{1}=0.023 \times R e_{1}^{0.8} \times P r_{1}^{0.3}, \operatorname{Re} \in(2000, \infty\rangle .
$$

Heat transfer coefficient on the flue gas side is calculated by Equation (16) [25]:

$$
h_{1}=\frac{N u_{1} \times \lambda}{d_{1}} \text {. }
$$

For the water side, we also have to consider the properties of flow. Firstly, we have to calculate velocity of water flowing around the pipes. Velocity $u_{2}$ is calculated from Equation (17) [25]:

$$
u_{2}=\frac{m_{2}}{\rho_{w} \times\left(a \times l-\left(n_{1} \times d_{2} \times l\right)\right)} .
$$

To find type of water flow, it is necessary to calculate the Reynolds number (Equation (18)) [25]:

$$
R e_{2}=\frac{2 \times u_{2} \times \pi \times d_{2}}{\vartheta_{2}} .
$$

The Prandtl number is calculated by Equation (19) [25]:

$$
\operatorname{Pr}_{2}=\frac{c_{2} \times \mu_{2}}{\lambda}
$$

Equation 20 is used to calculate the Nusselt number for a defined range of the Reynolds number [25]:

$$
N u_{2}=0.27 \times R e_{2}^{0.63} \times P r_{2}^{0.36} \times\left(\frac{P r_{2}}{P r_{2 w}}\right)^{0.25}, R e \in(1000,200000\rangle
$$

Heat transfer coefficient on flue gas side is calculated by Equation (21) [25]:

$$
h_{2}=\frac{2 \times N u_{2} x \times \lambda_{2}}{\pi \times d_{2}} .
$$

In our case, we have to achieve a compact boiler with the smallest possible area and height requirements. Maximal width and depth of the heat exchanger was set to $400 \mathrm{~mm}$. From the characteristics of flue gas flow, we can see that the main type of flow is laminar; when we choose a small amount of pipes or a small diameter of pipes, flow comes to a turbulent area, and demanded length is higher, with the maximal possible number of pipes in the demanded area.

The final arrangement with regard to the possibility of construction is shown in Figure 5.

From Figure 6 it is clear that, by decreasing diameter of heat exchanger's pipes, a higher heat transfer area is obtained. Our model was used to predict the heat power of a source by using different heat exchanger pipe diameters, with the maximal number of pipes in the floor plan. We can see that, by achieving the highest possible area of the heat exchanger, we will achieve the highest heat power, what is obvious from Figure 7. This model can be also used to calculate different configurations of heat sources, modulating it to obtain a high range of possible heat power levels and to achieve a high possible usability and adaptation of our heat source to small houses and also to small farms, and thus increasing the use of waste straw as fuel. 


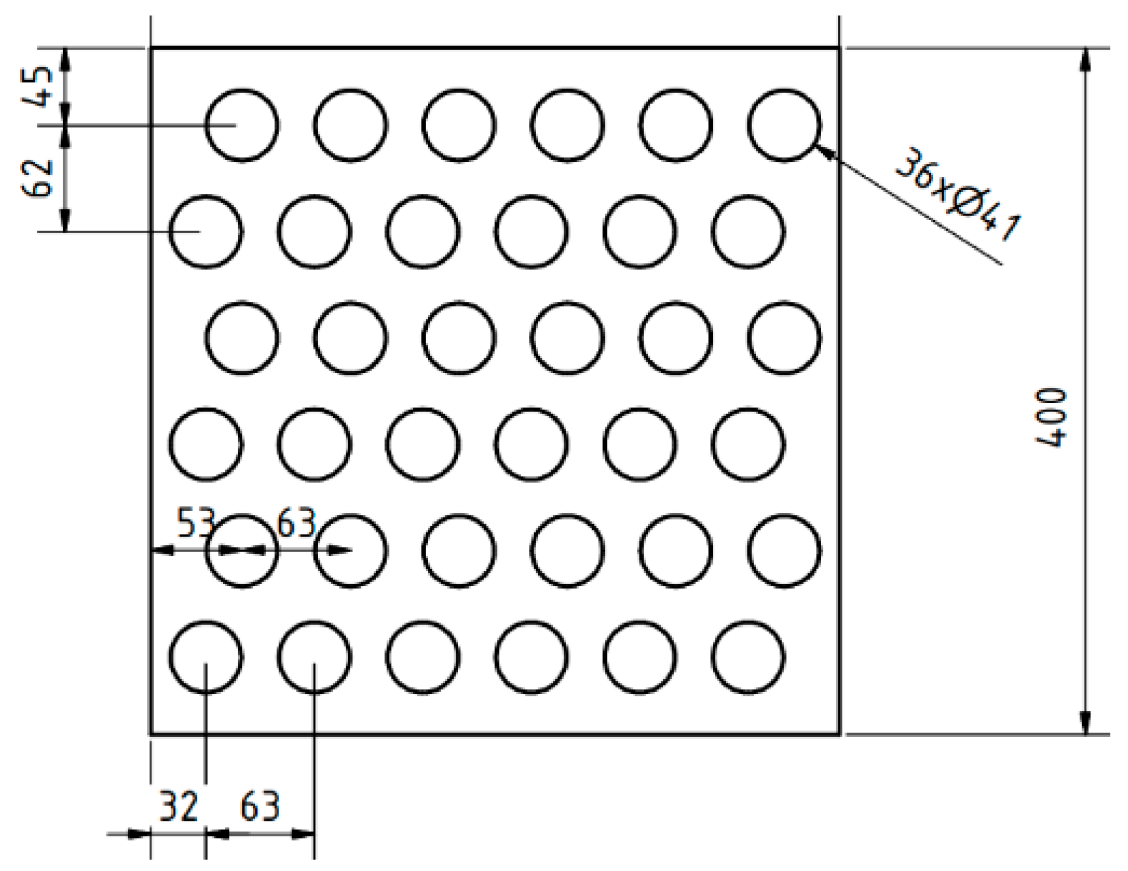

Figure 5. Final design of pipes arrangement.

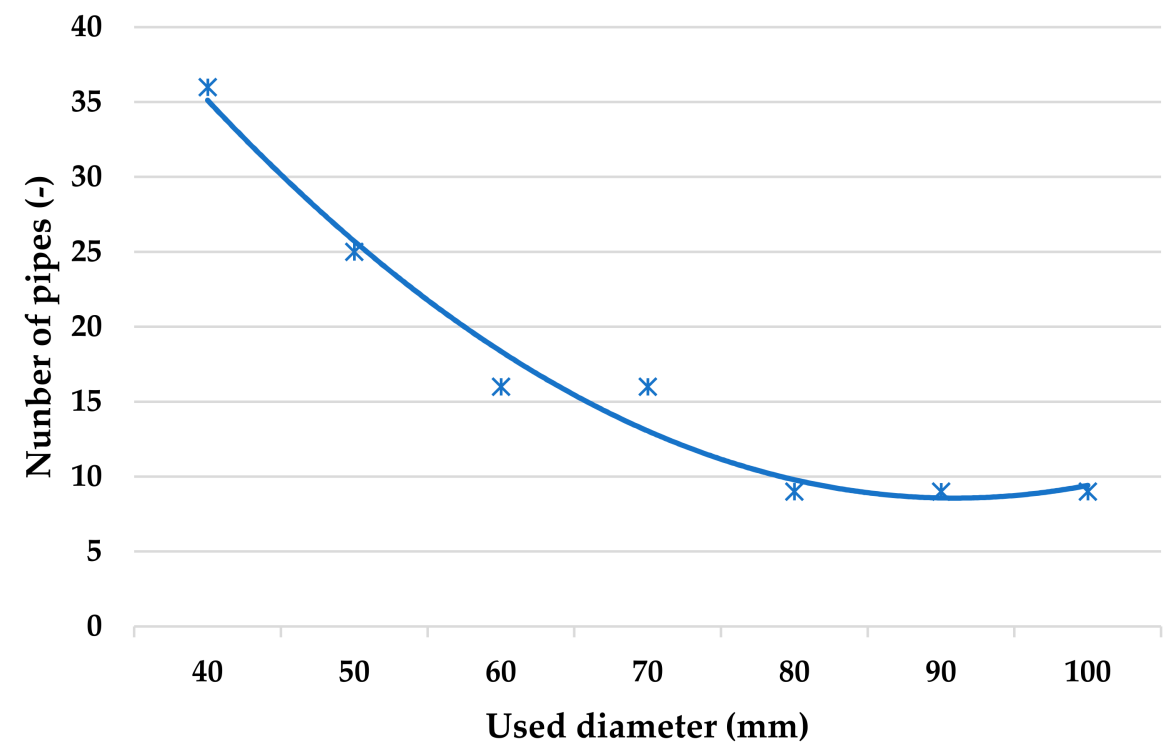

Figure 6. Maximal number of pipes by used outer diameter. 


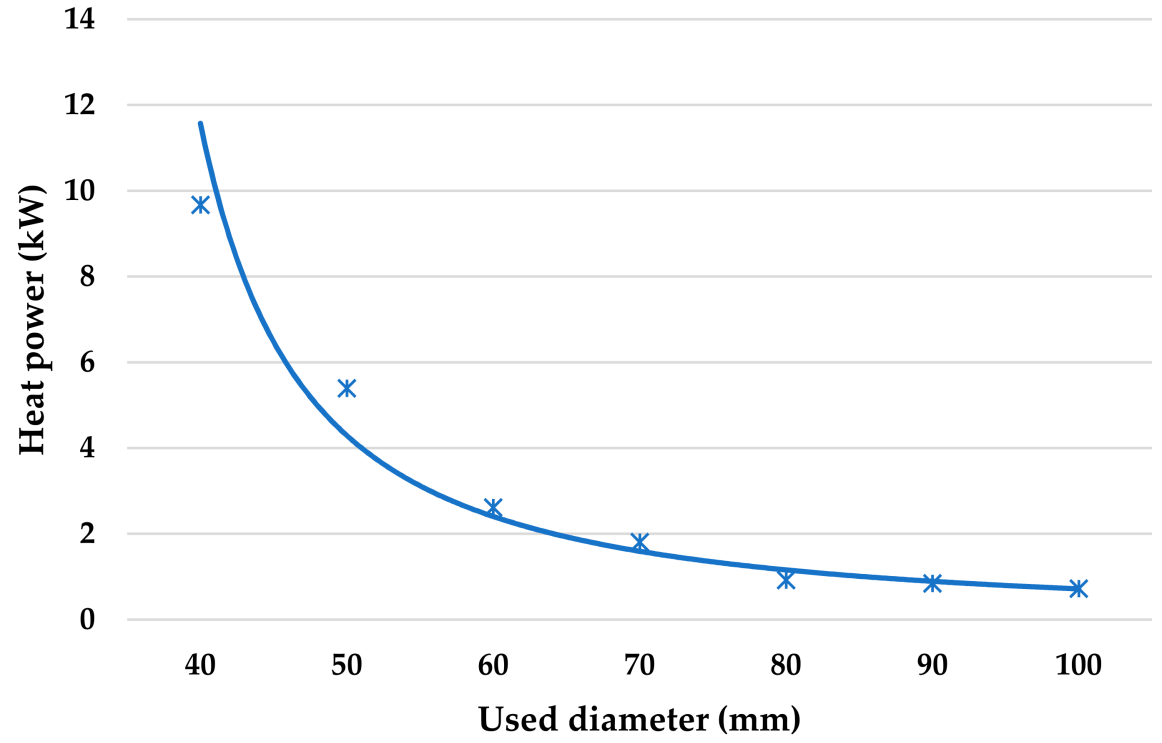

Figure 7. Maximal heat power of one-meter-long heat exchanger with different pipe diameters.

The resulting values of heat exchanger computation are shown in Table 3.

Table 3. Heat exchanger final design.

\begin{tabular}{ccc}
\hline Parameter & Value & Unit \\
\hline Inlet temperature of flue gas $\left(t_{11}\right)$ & 1040 & ${ }^{\circ} \mathrm{C}$ \\
Outlet temperature flue gas $\left(t_{12}\right)$ & 150 & ${ }^{\circ} \mathrm{C}$ \\
Inlet temperature of water $\left(t_{21}\right)$ & 50 & ${ }^{\circ} \mathrm{C}$ \\
Outlet temperature of water $\left(t_{22}\right)$ & 80 & ${ }^{\circ} \mathrm{Kg} \cdot \mathrm{s}^{-1}$ \\
\hline Flow of flue gas $\left(m_{1}\right)$ & $2.0128 \times 10^{-2}$ & $\mathrm{~kg} \cdot \mathrm{s}^{-1}$ \\
Flow of water $\left(m_{2}\right)$ & $1.5968 \times 10^{-1}$ & $\mathrm{~kW}$ \\
Demanded heat power $(Q)$ & 20 & $\mathrm{~m}$ \\
Depth of heat exchanger $(a)$ & $4 \times 10^{-1}$ & $\mathrm{~m}$ \\
Width of heat exchanger $(b)$ & $4 \times 10^{-1}$ & - \\
Number of pipes in rows $\left(n_{1}\right)$ & 6 & - \\
Number of pipes in columns $\left(n_{2}\right)$ & $6.2 \times 10^{-2}$ & $\mathrm{~m}$ \\
Inner diameter $\left(d_{1}\right)$ & $4 . \times 10^{-2}$ & $\mathrm{~m}$ \\
Outer diameter $\left(d_{2}\right)$ & Value & $\mathrm{Units}$ \\
\hline Calculated parameters & 492.24 & - \\
\hline Reynolds number of flue gas flow $\left(R e_{1}\right)$ & 4.49 & $\mathrm{~W} \cdot \mathrm{m}^{-1} \cdot \mathrm{K}^{-1}$ \\
Nusselt number of flue gas flow $\left(N u_{1}\right)$ & 8.13 & - \\
Flue gas side heat transfer coefficient $\left(h_{1}\right)$ & 14742 & - \\
Reynolds number of water flow $\left(R e_{2}\right)$ & 53.96 & $\mathrm{~W} \cdot \mathrm{m}^{-1} \cdot \mathrm{K}^{-1}$ \\
Nusselt number of water flow $\left(N u_{2}\right)$ & 915.37 & $\mathrm{~W} \cdot \mathrm{m}^{-1} \cdot \mathrm{K}^{-1}$ \\
Water side heat transfer $\left(h_{2}\right)$ & 8.05 & $\mathrm{~m}$ \\
Overall heat transfer coefficient $(k)$ & 1.62 & 1.5 \\
Proposed length $\left(L_{p r}\right)$ & 18.703 & \\
Chosen length $\left(L_{c h}\right)$ & & \\
Real heat power of heat exchanger $\left(Q_{r}\right)$ & & \\
\hline
\end{tabular}

To maintain the idea of modularity, and the possibility of having a working boiler even when one part of heat exchanger is broken, the final length of the heat exchanger was chosen to be $1.5 \mathrm{~m}$, also with decreased heat power. Our final design consists of nine elements, with can be differently assembled. The designed boiler is shown in Figure 8 . 


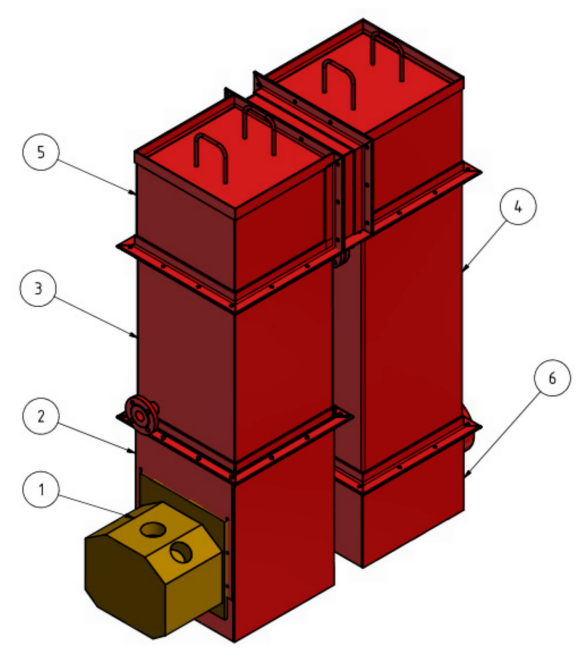

Figure 8. Final design of boiler. 1, burner; 2, combustion chamber; 3, primary heat exchanger; 4, secondary heat exchanger; 5 , top chamber.

\subsubsection{Design of Heat Exchanger by Using CFD}

We designed a CFD model for the pipe area, shown in Figure 9a-flue gas in Ansys 20.1-workbench to compare and verify our numerical model. CFD model was implemented using a fluid flow (fluent) analysis system. For the calculation, a simplified 3D model with flue gas phase was used.

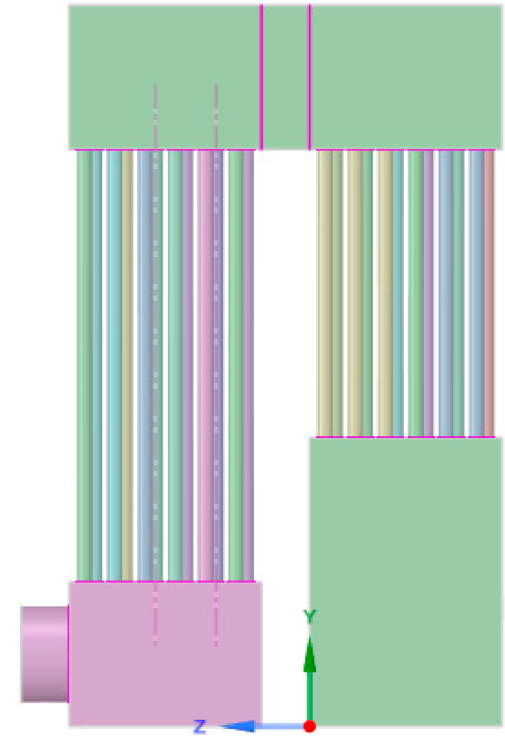

(a)

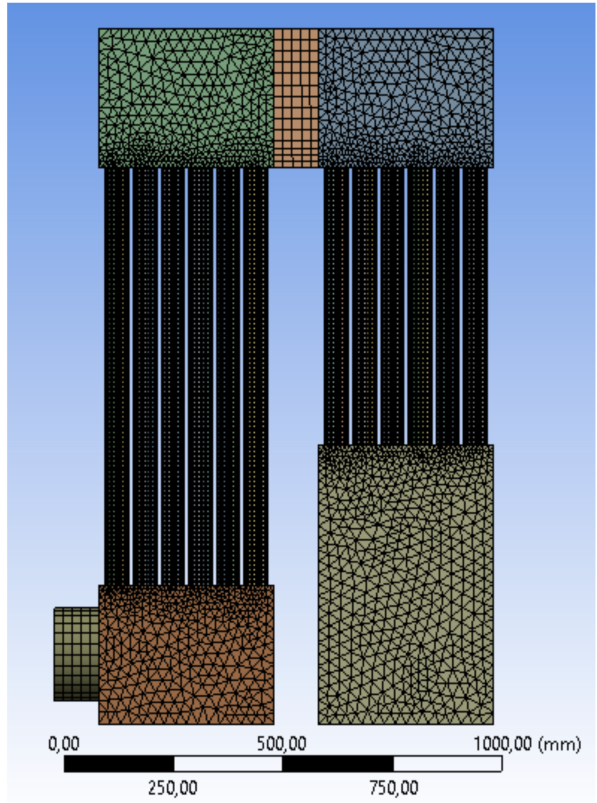

(b)

Figure 9. Designed (a) and meshed (b) model in Ansys 20.1.

The meshed complete model, shown in Figure 9b, had nearly 4.5 million elements. The shape of elements was a combination of tetragonal and hexagonal. The model was divided into smaller parts to obtain better mesh quality. The quality of the mesh was assessed based on the orthogonal quality with an average value of 0.84 , the skewness with an average value of 0.2 , and the aspect ratio with an average value of 1.86 . Based on the evaluation criteria, the quality of the mesh was recognized as sufficient.

Grid sensitivity was increased to obtain better results. The denser mesh was created. Differences in the results were insignificant and less dense mesh was used to analyze the model. 
Boundary conditions were set up to mass flow on the inlet and outflow. Mass flow was calculated by using calorimetric calculations for maximum heat power of heat exchanger, which was $20 \mathrm{~kW}$. Mass flow of flue gas (mass flow of inlet) was set to $2.0128 \times 10^{-2} \mathrm{~kg} \cdot \mathrm{s}^{-1}$. The pressure at the outlet was set at $-12 \mathrm{~Pa}$, and a suitable value for the chimney draft was from 10 to $14 \mathrm{~Pa}$, according to STN EN 13,240. For the walls of the heat exchanger the mean temperature of water was set. The temperature was set to $65^{\circ} \mathrm{C}$. To calculate this, the $\mathrm{K}-\varepsilon$ model with scalable wall function was used. The radiative transfer equation for modeling radiation intensity was integrated over solid angles using the discrete ordinates method $[27,28]$.

We can see from Figure 10 that the temperature field in the combustion chamber has a constant value. This is caused by the use of a constant temperature of flowing inlet flue gas. This calculation is usable for the fast prediction of exchanger heat power by CFD. Temperature and velocity fields do not correspond with the real model.

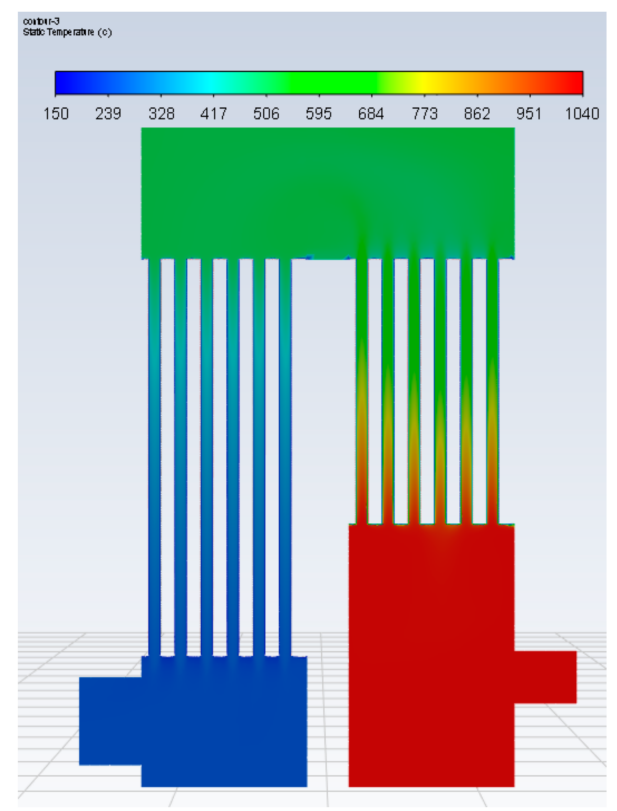

(a)

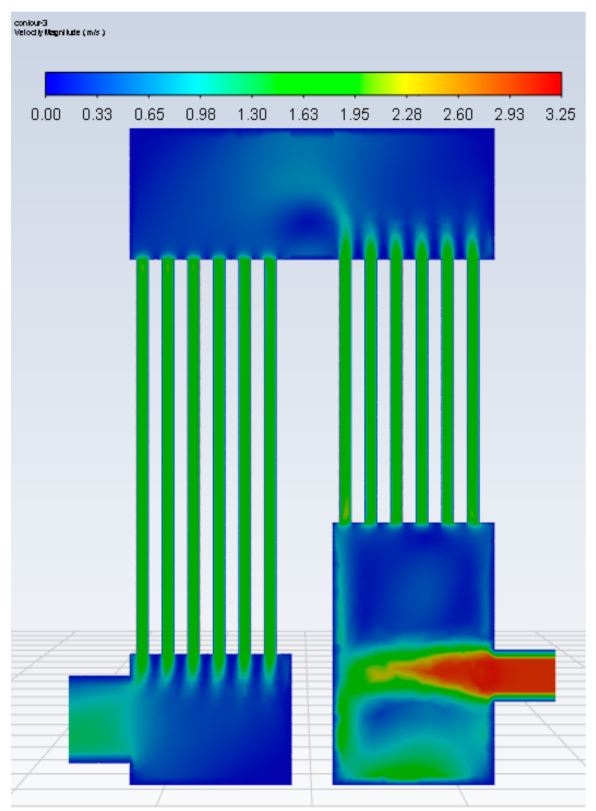

(b)

Figure 10. Temperature (a) and velocity (b) field of the designed boiler with constant inlet flow, with constant temperature.

\subsubsection{Design of Heat Exchanger by Using CFD Combustion Model}

For a better solution, we used an improved model. It is necessary to include the model of combustion. Mesh was used from previous calculations. The K- $\varepsilon$ model with scalable wall function was also used, but with species transport. Species transport with soot model, and diffusion energy source model were used to simulate combustion. The type of reactions was set to volumetric. Turbulence of chemical interactions was set to eddy dissipation with properties of wheat straw from Table 1 . The mass flow of flue gas, $2.0128 \times 10^{-2} \mathrm{~kg} \cdot \mathrm{s}^{-1}$, was set to the inlet. The mass flow consists of volatile $(8.2 \%)$ and air $(91.8 \%)$.

From Figure 10 we can see that maximal temperature of temperature field is higher in the combustion model, but the mean temperature is the same. From Figure 11 it is obvious that flue gas does not flow through every pipe. In future designs, baffles should be used to uniform distribution of flue gas. It will lead to obtaining optimal heat distribution all over the heat transfer area, but also to the reduction in the flue gas of wheat straw fouling the heat exchanger. 


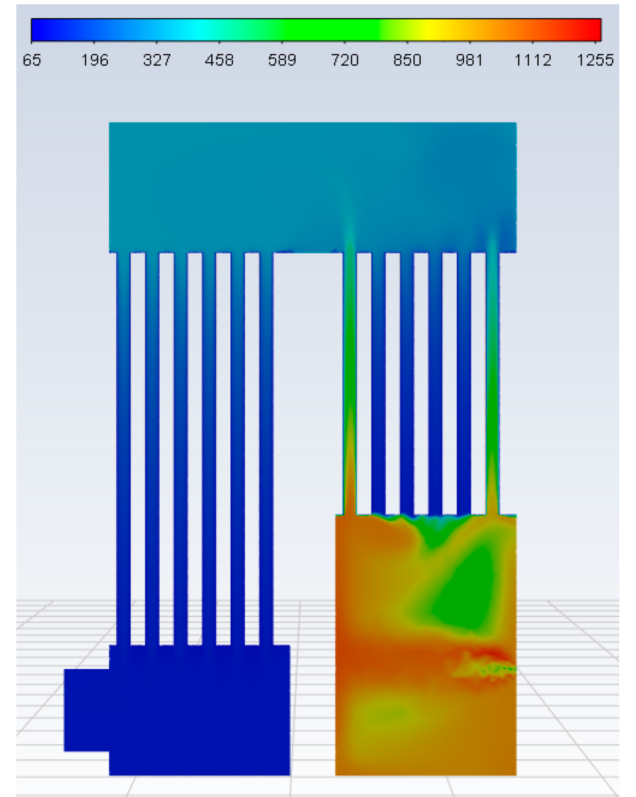

(a)

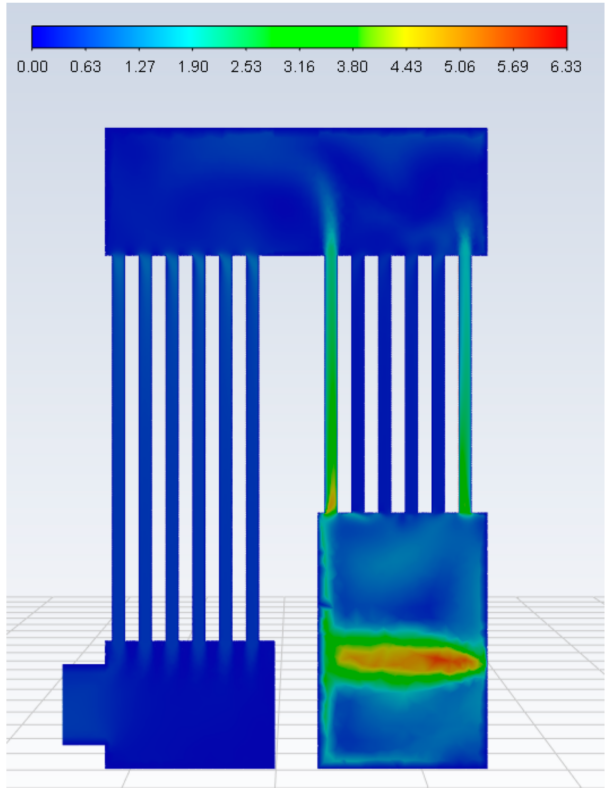

(b)

Figure 11. Temperature (a) and velocity (b) field of designed boiler by using combustion model.

\subsubsection{Final Evaluation of Designed Heat Exchanger}

In Figure 12, we can see that the difference between the simple mathematical model, the CFD model and the CFD combustion model is not large. Differences can be caused by the neglect of pollution of the heat exchanger in the mathematical model. This neglect is not significant, and our simple mathematical model and CFD model are usable for a fast simple design of wheat straw boiler. From the CFD model of combustion, it is obvious that flue gas flows directly to the wall. It is necessary to direct flow to the heat exchanger, which should absorb the highest possible amount of power from combustion. Innovations such as using baffles and different combinations of parts could lead to better construction. Coagulation of soot can help to find critical points of clogging, and these can be removed with simple improvements [28]. The model can be also used to design a series of boilers with different heat powers and different combinations.

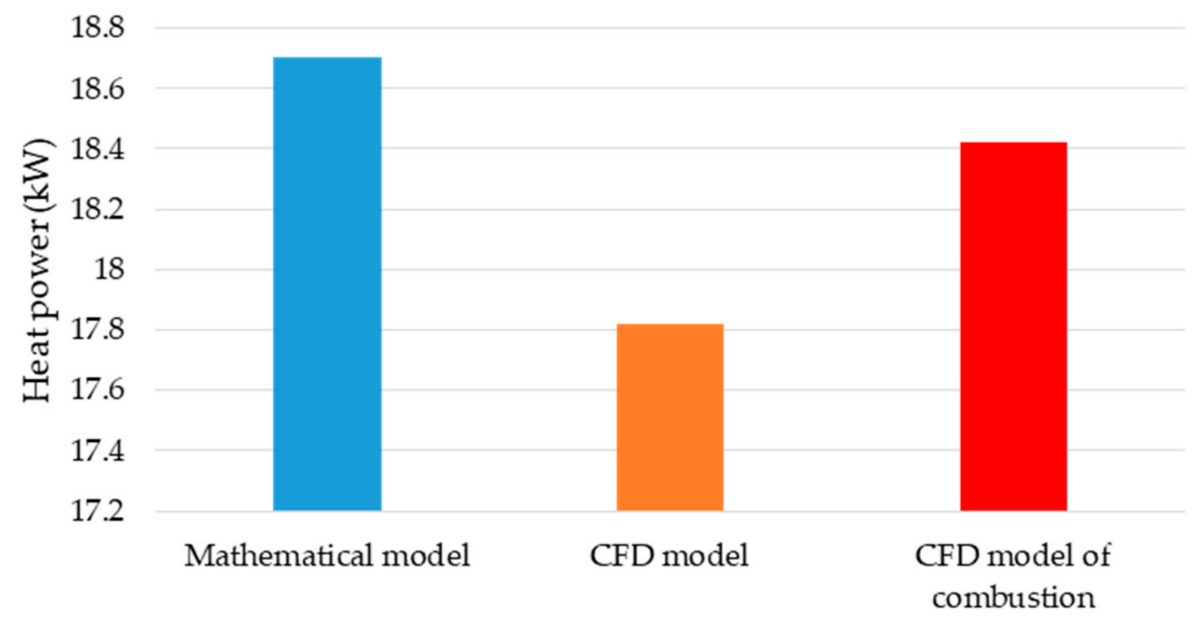

Figure 12. Comparison of calculated heat power.

\section{Conclusions}

It is obvious from numerical and CFD simulations that, by using different views to simulate of our heat boiler, we can achieve similar solutions. The difference between the 
simplified CFD model and the combustion model is notable by comparison of the velocity field. From the combustion model, we can see the difference between the velocity fields in the pipes, which should be improved by simply using baffles. Using baffles can also extend the life of the heat exchanger, because they will mean it will not be directly exposed to flue gases from straw combustion. We can say that, for the basic design of the heat exchanger, a simple mathematical model can be used. With designed geometry, this model can be extended to include to CFD simulation, which can allow the final construction optimization of boiler. By comparison to existing boilers, for example Dongji Wang's [18], which used combustion of wheat straw, our concept of boiler is mainly different because it uses the modularizing principle, using only one pass firing biomass, and using a rotary burner, which by its construction predetermines the designed boiler to burn biomass fuel with different properties, and to burn waste straw from agricultural production. Both designs use input parameters of combusted fuel, but Dongii Wang's [18] design calculates the heat power of the source by heat loss method, which contains heat losses by flue gas. These losses are used to calculate the power gained from combustion. In our model, we used calorific value, temperature of combustion chamber, basic and criterial equations to calculation of heat power of combustion. A basic design is used as input to the CFD simulations, which provide a more precise result, and allow for the design of further innovations. In comparison to manual calculations of heat transfer area, the CFD model presents a way of designing a boiler which is smarter and has more potential. The construction contains a tubular heat exchanger, which is similar to big boilers designed by Mladenovic [15], but it is used as small heat source. This construction allows simple service, and in an emergency, allows for the continued functioning of the boiler during partial failure of the heat exchanger, which also means simpler cleaning, and allows for the use of simple improvements of construction. Future research will lead to finding solutions that can lead to the use of this boiler without using a rotary burner and the design of direct firing straw, by further improvement of the combustion chamber. The purchase price will be decreased. It should lead to a simple, cheap, modular boiler, which can indirectly support small farms and increase agriculture production in developing regions.

Author Contributions: M.P., investigation, conceptualization, writing-original draft; M.H., data curation; A.K., formal analysis; P.D., writing—review and editing, data curation.; M.M., data curation. All authors have read and agreed to the published version of the manuscript.

Funding: This research was funded by the project VEGA 1/0233/19 "Construction modification of the burner for combustion of solid fuels in small heat sources".

Institutional Review Board Statement: Not applicable.

Informed Consent Statement: Not applicable.

Data Availability Statement: Data available in a publicly accessible repository.

Conflicts of Interest: The funders had no role in the design of the study; in the collection, analyses, or interpretation of data; in the writing of the manuscript, or in the decision to publish the results.

\section{References}

1. Nielsen, C. Utilisation of straw and similar agricultural residues. Biomass Bioenergy 1995, 9, 315-323. [CrossRef]

2. Voytenko, Y.; Peck, P. Organisational frameworks for straw-based energy systems in Sweden and Dennmark. Biomass Bioenergy 2012, 38, 34-48. [CrossRef]

3. Alsos, G.; Lunggren, E.; Pettersen, L.T. Farm-based entrepreneurs: What triggers the start-up of new business activities? Small Bus. Enterp. Dev. 2003, 10, 435-443. [CrossRef]

4. Simmons, B. Straw in Skane: The Imminent Development of the Skane Straw Market Triggered by the Ortofta Biomass Boiler. Master's Thesis, Department of Economic History Economic Growth, Innovation and Spatial Dynamics, Lund University, Lund, Sweden, 2008.

5. Perea-Moreno, M.A.; Sameron-Manzano, E.; Perea-Moreno, A.J. Biomass as Renewable Energy: Worldwide Research Trends. Sustainability 2019, 11, 863. [CrossRef]

6. Gradziuk, P.; Gradziuk, B.; Trocewicz, A.; Jendrzejewski, B. Potential of Straw for Energy Purposes in Poland-Forecasts Based on Trend and Causal Models. Energies 2020, 13, 5054. [CrossRef] 
7. Mzurkiewicz, J.; Marczuk, A.; Pochwatka, P.; Kujawa, S. Maize straw as a valuable energetic material for biogas plant feeding. Materials 2019, 12, 3848. [CrossRef] [PubMed]

8. Smil, V. Crop residues: Agriculture's largest harvest. Bioscience 1999, 49, 299-308. [CrossRef]

9. Edwards, R.A.H.; Śúri, M.; Huld, T.A.; Dallemand, J.F. GIS-Based Assessment of Cereal Straw Energy Resource in the European Union. Available online: http:/ / citeseerx.ist.psu.edu/viewdoc/download?doi:10.1.1.550.9051\&rep=rep1\&type=pdf (accessed on 2 February 2021).

10. Elbersen, B.; Startisky, I.; Hengeveld, G.; Schelhaas, M.; Nae, H.; Böttcher, H. Biomass role in achieving the Climate Change \& Renewables EU policy targets. Demand and Supply dynamics under the perspective of stakeholders. In Atlas of EU Potentials; ALTERRA: Copenhagen, Denmark, 2011. Available online: https:/ / ec.europa.eu/energy/intelligent/projects/sites/ieeprojects/files/projects/documents/biomass_futures_atlas_of_technical_and_economic_biomass_potential_en.pdf (accessed on 2 February 2021).

11. Seglah, P.A.; Wang, Y.; Wang, H.; Bi, Y. Estimation and Efficient Utilization of Straw Resources in Ghana. Sustainability 2019, 11, 4172. [CrossRef]

12. Moliner, C.; Bove, D.; Arato, E. Co-Incineration of Rice Straw-Wood Pellets: A Sustainable Strategy for the Valorisation of Rice Waste. Energies 2020, 13, 5750. [CrossRef]

13. Nosek, R.; Werle, S.; Borsukiewicz, A.; Zelazna, A.; Łagód, G. Investigation of Pellet Properties Produced from a Mix of Straw and Paper Sludge. Appl. Sci. 2020, 10, 5450. [CrossRef]

14. Chungen, Y. Development in biomass preparation for suspension firing towards higher biomass shares and better boiler performance and fuel rangeability. Energy 2020, 196, 117129.

15. Mladenovic, R.; Dakic, D.; Eric, A.; Mladenovic, M.; Paprika, M.; Repic, B. The boiler concept for combustion of large soya straw bales. Energy 2009, 34, 715-723. [CrossRef]

16. Perez-Jeldre, R.; Cornejo, P.; Flores, M.; Gordon, A.; García, X. A modeling approach to co-firing biomass/coal blends in pulverized coal utility boilers: Synergistic effects and emissions profiles. Energy 2017, 120, 663-674. [CrossRef]

17. Cai, Y.; Tay, K.; Zheng, Z.; Yang, W.; Wang, H.; Zeng, G.; Li, Z.Z.; Boon, K.; Subbaiah, P. Modeling of ash formation and deposition processes in coal and biomass fired boilers: A comprehensive review. Appl. Energy 2018, 230, 1447-1454. [CrossRef]

18. Wang, D.; Liu, L.; Yuan, Y.; Yang, H.; Zhou, Y.; Duan, R. Design and key heating power parameters of a newly-developed household biomass briquette heating boiler. Renew. Energy 2019, 147, 1371-1379. [CrossRef]

19. Brzeski, M. The Unit for Supplying Air to the Combustion Chamber of Pellet Burner. WO 2016/056930 A2, 14 April 2016.

20. Jia, G.; Li, L.; Zhang, D.M. Effect Analysis on Combustion and Emission Characteristics of a Rotary Burner Fueled by Biomass Pellet Fuel. J. Chem. 2020, 2020, 3618382. [CrossRef]

21. Kulokas, M.; Praspaliauskas, M.; Pedišius, N. Investigation of Buckwheat Hulls as Additives in the Production of Solid Biomass Fuel from Straw. Energies 2021, 14, 265. [CrossRef]

22. Jansky, J. Steam Boilers; SNTL: Praha, Czech Republic, 1954; p. 296.

23. Setnicka, F. Thermal Engineering for Wood Engineers; ALFA: Bratislava, Slovakia, 1981; p. 432.

24. Trnobransky, K. Analysis of wood waste burning process. Wood 1976, 31, 237-240.

25. Icropera, F.P.; Dewitt, D.P.; Bergman, T.L.; Lavine, A.S. Fundamentals of Heat and Mass Transfer; John Wiley \& Sons: New York, NY, USA, 2007.

26. Lenhard, R.; Kaduchova, K.; Papučik, S.; Jandačka, J. Utilization of heat pipes for transfer heat from the flue gas into the heat transfer medium. EPJ Web Conf. 2014, 67, 02067. [CrossRef]

27. Čajová Kantová, N.; Sładek, S.; Jandačka, J.; Čaja, A.; Nosek, R. Simulation of Biomass Combustion with Modified Flue Gas Tract. Appl. Sci. 2021, 11, 1278. [CrossRef]

28. Čajová Kantová, N.; Čaja, A.; Patsch, M.; Holubčík, M.; Ďurčanský, P. Dependence of the Flue Gas Flow on the Setting of the Separation Baffle in the Flue Gas Tract. Appl. Sci. 2021, 11, 2961. [CrossRef] 